\title{
THE INFLUENCE OF PRANDTL NUMBER ON FREE CONVECTION IN A RECTANGULAR CAVITY
}

\author{
W. P. GraebeL \\ Department of Mechanical Engineering and Applied Mechanics, \\ The University of Michigan, Ann Arbor, MI. 48109, U.S.A.
}

(Received 19 May 1980)

\begin{abstract}
Natural convection in a rectangular cavity is considered for the problem where one vertical wall is heated and the other is cooled. The boundary layer flow is solved using a modified Oseen technique in a manner similar to Gill's solution. Temperature and velocity profiles in the core, and the Nusselt number, are found as functions of the Rayleigh and Prandtl numbers and the length ratio. The solution indicates that for a Prandtl number less than $1 / 7$, a midsection shear layer develops.
\end{abstract}

\section{NOMENCLATURE}

C, constant of integration;

$g$, gravitational constant;

$H$, cavity height;

K, $=(\operatorname{Pr}-1) /(\operatorname{Pr}+1)$;

$L$, cavity length;

$\mathrm{Nu}$, Nusselt number;

$p$, pressure;

Pr, Prandtl number;

$q, \quad=2 u_{A} / v^{2}(K+1)^{3}$;

$Q$, total heat flux;

$R a, \quad=\beta g L^{3}\left(T_{L}-T_{R}\right) / v \alpha$, Rayleigh number;

$T$, temperature;

$u, w$, velocity components, $u=\partial \psi / \partial z, w=$ $-\partial \psi / \partial x$

$v, \quad=\lambda_{1}+\lambda_{2}-\lambda_{3}-\lambda_{4}$

$x, z, \quad$ coordinates.

Greek symbols

$\alpha$, thermal diffusivity;

$\beta$, thermal expansivity;

$\varepsilon, \quad=\left(L^{3} / H^{3} R a\right)^{1 / 4}$

$\lambda$, roots of characteristic equation;

$v, \quad$ kinematic viscosity;

$\psi$, two-dimensional stream function.

Subscripts and superscripts

$A$, averaged value;

$L, \quad$ left cavity wall;

$R$, right cavity wall;

0 , core quantity;

* dimensional quantity.

\section{INTRODUCTION}

THE PROBLEM of natural convection in a rectangular cavity when the two walls are maintained at different temperatures was first solved by Gill [1] for the case where the heat transfer is due almost entirely to convection. He, however, considered only the infinite Prandtl number limit, and handled the matching of the core flow with the top and bottom boundary layers in a somewhat artificial manner. Bejan [2] has shown a more reasonable matching condition and obtained overall Nusselt numbers which are in good agreement with available experimental and numerical heattransfer data.

The present note generalizes Gill's results for arbitrary values of the Prandtl number, so that the small Prandtl number limit, suitable for liquid metals, can also be obtained. The method of Bejan is used in evaluating the constant of integration which appears in the solution.

\section{BASIC ASSUMPTIONS}

The height of the cavity is taken as $H$ and the horizontal spacing of the walls as $L$. The vertical walls are at the constant temperatures $T_{L}$ on the left and $T_{R}$ on the right of the cavity. Dimensionless variables suited to a boundary layer on the left wall are introduced according to

$$
\begin{gathered}
x=x^{*} / \varepsilon H, \quad z=z^{*} / H, \\
T=\left[T^{*}-0.5\left(T_{L}+T_{R}\right)\right] /\left(T_{L}-T_{R}\right), \\
\psi=\psi^{*} \varepsilon / \alpha, \quad p=p^{*} / \rho \beta g H\left(T_{L}-T_{R}\right),
\end{gathered}
$$

where quantities with asterisks are dimensional, and $R a$ and $P r$ are the Rayleigh and Prandtl numbers. The energy and Navier-Stokes equations become, under this transformation,

$$
\begin{gathered}
u \frac{\partial T}{\partial x}+w \frac{\partial T}{\partial z}=\frac{\partial^{2} T}{\partial x^{2}}+\varepsilon^{2} \frac{\partial^{2} T}{\partial z^{2}} \\
\left(\varepsilon^{2} / \operatorname{Pr}\right)\left(u \frac{\partial u}{\partial x}+w \frac{\partial u}{\partial z}\right)=-\frac{\partial p}{\partial x}+\varepsilon^{2} \frac{\partial^{2} u}{\partial x^{2}}+\varepsilon^{4} \frac{\partial^{2} u}{\partial z^{2}} \\
(1 / \operatorname{Pr})\left(u \frac{\partial w}{\partial x}+w \frac{\partial w}{\partial z}\right)=-\frac{\partial p}{\partial z}+T+\frac{\partial^{2} w}{\partial x^{2}}+\varepsilon^{2} \frac{\partial^{2} w}{\partial z^{2}}
\end{gathered}
$$

The boundary layer thickness parameter $\varepsilon$ will be assumed small compared to the length ratio $L / H$, and $\varepsilon^{2} / \operatorname{Pr}$ small compared to unity. The boundary layer equations are then obtained by formally letting $\varepsilon$ be zero in equations (1), (2) and (3).

In the core of the cavity, the stream function, temperature, and vertical distance are scaled the same 
as in the boundary layer to allow matching of the boundary layer and interior solutions. When convection is the principal driving force, it is expected that the temperature in the core will vary only with the vertical coordinate, and that the streamlines will be nearly horizontal. From the energy equation, it follows that in the core

$$
w=w_{0}(z)=r^{2} \begin{array}{c|c}
\mathrm{d}^{2} T_{0} \\
\mathrm{~d} z^{2}
\end{array} / \begin{gathered}
\mathrm{d} T_{0} \\
\mathrm{~d} z
\end{gathered} .
$$

Hence the stream function in the core is, to the lowest two orders,

$$
\begin{aligned}
& \psi(x, z)=\psi_{0}(z)+\varepsilon\left[-\left(x^{*}-L / 2\right)\right. \\
& \left.\times \frac{\mathrm{d}^{2} T_{0}}{\mathrm{~d} z^{2}} / H \frac{\mathrm{d} T_{0}}{\mathrm{~d} z}+\psi_{1}(z)\right] .
\end{aligned}
$$

\section{BOUNDARY LAYER SOLUTION}

Using a modified Oseen technique suggested by Carrier [3], the convective terms in the boundary layer equations are linearized by using values for the horizontal velocity and vertical temperature gradient which are averaged. These averaged values are then determined by assuring that global mass and energy balances are achieved. Under this approximation the boundary layer equations of energy and vertical momentum become

$$
\begin{gathered}
u_{A} \frac{\partial T}{\partial x}+w \frac{\mathrm{d} T_{A}}{\mathrm{~d} z}=\frac{\partial^{2} T}{\partial x^{2}}, \\
u_{A} \frac{\partial w}{\partial x} / \operatorname{Pr}=T-T_{0}+\frac{\partial^{2} w}{\partial x^{2}} .
\end{gathered}
$$

The $A$ subscript indicates the averaged values.

A set of coordinate axes will be used with origin at the midpoint of the left boundary of the cavity. The solution of equations (5) and (6) near the left vertical boundary which satisfies the no-slip and isothermal conditions and matches with the core flow is

$$
\begin{array}{r}
\psi(x, z)=\psi_{0}(z)\left[1-\left(\lambda_{2} \mathrm{e}^{-\lambda_{1} x}\right.\right. \\
\left.\left.-\lambda_{1} \mathrm{e}^{-\lambda_{2} x}\right) /\left(\lambda_{2}-\lambda_{1}\right)\right], \\
T(x, z)=T_{0}(z)-\lambda_{1} \lambda_{2} \psi_{0}(z)\left[\lambda_{2}\left(\lambda_{2}+u_{A} / \operatorname{Pr}\right) \mathrm{e}^{-\lambda_{2} x}\right. \\
\left.-\lambda_{1}\left(\lambda_{1}+u_{A} / \operatorname{Pr}\right) \mathrm{e}^{-\lambda_{1} x}\right] /\left(\lambda_{2}-\lambda_{1}\right),
\end{array}
$$

with

$$
\psi_{0} \lambda_{1} \lambda_{2}\left(\lambda_{1}+\lambda_{2}+u_{A} / \operatorname{Pr}\right)=T_{0}-1 / 2 .
$$

The parameters $\lambda_{1}, \lambda_{2}$ are functions of $z$, and are the two roots with positive real parts of

$$
\lambda^{2}\left(\lambda+u_{A}\right)\left(\lambda+u_{A} / \operatorname{Pr}\right)+\mathrm{d} T_{A} / \mathrm{d} z=0 .
$$

Symmetry suggests that $T_{0}$ will be an odd function of $z$, and $\psi_{0}$ an even function of $z$. Hence, $u_{A}$ and $T_{A}$ will both be odd functions of $z$. When $u_{A}$ is positive (flow from the left boundary layer into the core) the roots $\lambda_{1}$ and $\lambda_{2}$ will be complex, and thus the boundary layer portions of the velocity and temperature fields will exhibit oscillatory decay. Where $u_{A}$ is negative (flow into the boundary layer) the roots $\lambda_{1}, \lambda_{2}$ will be real. with simple exponential decay.

Since equation (10) is invariant under the simultaneous sign change of $z$ and $\lambda$, it follows that

$$
\lambda_{3}(z)=-\lambda_{1}(-z) \cdot \lambda_{4}(z)=\cdots \lambda_{2}(-x)
$$

Thus if the same $u_{A}$ and $T_{4}$ are used on both of the vertical walls of the cavity, the stream functions and temperature near the right wall will have the same general form as equations (7), (8) and (9), but with $x$ replaced by $\left(L-x^{*}\right) / \varepsilon H, \lambda_{1}(z), \lambda_{2}(z)$ by $\lambda_{1}(-z)$, $\lambda_{2}(-z)$, and some sign changes.

To complete determination of the core flow, the energy change in the boundary layer is required to be due entirely to the transfer from the wall and the core. Integration of equation (1) over the left boundary layer gives

$$
\frac{\mathrm{d}}{\mathrm{d} z} \int_{0}^{\infty} \frac{\partial \psi}{\partial x}\left(T-T_{0}\right) \mathrm{d} x+\psi_{0} \frac{\mathrm{d} T_{0}}{\mathrm{~d} x}=\left.\frac{\partial T}{\partial x}\right|_{x=0} .
$$

Substitution of equations (7) and (8) gives

$$
\begin{aligned}
& \frac{\mathrm{d}}{\mathrm{d} z}\left[\frac{\left(1 / 2-T_{0}\right)^{2}}{2\left(\lambda_{1}+\lambda_{2}\right)\left[\lambda_{1}+\lambda_{2}+u_{A} / \operatorname{Pr}\right]^{2}}\right]-\psi_{0} \frac{\mathrm{d} T_{0}}{\mathrm{~d} z} \\
& =\left(1 / 2-T_{0}\right)\left[\lambda_{1}+\lambda_{2}-\lambda_{1} \lambda_{2} /\left(\lambda_{1}+\lambda_{2}+u_{A} / \operatorname{Pr}\right)\right] .
\end{aligned}
$$

Equations (9) and (12), along with their counterparts on the right vertical wall, contain the four unknowns $\psi_{0}, T_{0}, u_{A}, T_{A}$. Their solution is made much easier by the introduction of new variables $q$ and $v$ according to

$$
\begin{gathered}
v=\lambda_{1}+\lambda_{2}-\lambda_{3}-\lambda_{4}>0 . \\
q=2 u_{A} / v(K+1) .
\end{gathered}
$$

with

$$
K=(\operatorname{Pr}-1) /(P r+1) .
$$

The parameter $K$ varies between minus one (Prandtl number equals zero) and plus one (Prandtl number equals infinity). The use of the set of parameters $l, q, K$ makes the details of the calculation procedure fairly uniform in Prandtl number, at least (as will be seen) for Prandtl number greater than $1 / 7$.

Introducing the variables $v, q$ and $K$ into equation (10), the result is

$$
\begin{gathered}
\lambda_{1}+\lambda_{2}=v(1-q) / 2, \\
\lambda_{1} \lambda_{2}=v^{2}\left(1-K^{2} q^{2}\right)(1-q) / 8 \\
\lambda_{1}, \lambda_{2}=v(1-q \pm i[(1-q)(1+q) \\
\left.\left.\left.-2 K^{2} q^{2}\right)\right]^{1 / 2}\right\} / 4
\end{gathered}
$$

and

$$
\mathrm{d} T_{A} / \mathrm{d} z=v^{4}\left(1-K^{2} q^{2}\right)^{2}\left(1-q^{2}\right) / 64 .
$$

Substituting equations (16) and (17) into (9), and taking into consideration the corresponding equation on the right wall, the result is 


$$
\begin{gathered}
\psi_{0}=-8 / v^{3}\left(1-K^{2} q^{2}\right)\left(1+K q^{2}\right), \\
T_{0}=q(K+1) / 2\left(1+K q^{2}\right) .
\end{gathered}
$$

A similar procedure with equation (12) yields, after a good deal of algebra,

$$
\begin{aligned}
v=2(1- & \left.q^{2}\right)^{(K-3) / 3(K+1)} \\
\times[ & {\left[1+K(2+K) q^{2}\right]^{\left(2 K^{2}+9 K+11\right) / 3(K+1)(K+2) /} } \\
C(1 & \left.+K q^{2}\right)^{2 / 3}\left(1-K^{2} q^{2}\right)^{2 / 3} \\
\mathrm{~d} z / \mathrm{d} q= & C^{4}\left[4 K+3-K(3 K+5) q^{2}+K^{3} q^{4}\right] \\
& \times\left(1+K q^{2}\right)^{2 / 3}\left(1-K^{2} q^{2}\right)^{5 / 3} / \\
& 2\left(1-q^{2}\right)^{(7 K-9) / 3(K+1)}[1+K(2 \\
& \left.\left.+K) q^{2}\right)\right]^{\left(11 K^{2}+45 K+50\right) / 3(K+1)(K+2)}
\end{aligned}
$$

where $C$ is a positive constant of integration. The relation between $q$ and $z$ is thus found by integrating equation (23) from $q=0$, where $z=0$. The functions $v$, $T_{0}$ and $\psi_{0}$ are found as functions of $z$ by substitution into the appropriate expression.

\section{DETERMINATION OF THE INTEGRATION CONSTANT AND NUSSELT NUMBER}

The constant $C$ remains to be determined. (The value of $\lambda_{1}+\lambda_{2}$ at $z=0$ is $1 / C$; thus $C$ is a measure of the boundary layer thickness at the midpoint of the cavity.) Gill used the condition that the net flow in the boundary layer be zero at the top and bottom of the cavity $(z= \pm 1 / 2)$, giving for the large Prandtl number limit $C=0.912$. For this value, $T_{0}=1 / 2$ at $z=1 / 2$, and $\lambda_{1}, \lambda_{2}$ become infinite at $z=-1 / 2$.

As pointed out by Bejan [2], the condition used by Gill is not conceptually the best. It is applied in a region where the solution itself is not applicable, and if an adiabatic rather than an impermeable condition were required at the top and bottom of the cavity, the condition cannot be met by the boundary layer solution at any $z$. The results of imposing the impermeability condition are infinite horizontal velocities in the interior, and infinite vertical temperature gradients in the boundary layer.

As an alternative, Bejan suggested that if the top and bottom boundaries are insulated, a condition of zero vertical energy flux on the vertical boundary layer and core solutions is more likely to match the core solution to the horizontal boundary layers. These boundary layers then are of the conventional type, and act mainly to meet the no-slip requirement.

By integrating the energy equation across the width of the cavity, Bejan found, in terms of the present dimensionless variables, that

$$
\frac{\mathrm{d} Q}{\mathrm{~d} z}=\left.\frac{\partial T}{\partial x}\right|_{x=0} ^{x=L / \varepsilon H}
$$

where

$$
Q=\int_{0}^{L / \varepsilon H}\left(w T-\varepsilon^{2} \frac{\partial T}{\partial z}\right) \mathrm{d} x .
$$

Substitution of the previous boundary layer solution gives

$$
\begin{gathered}
\int_{0}^{L / \varepsilon H} w T \mathrm{~d} x=2 / v^{3}\left(1+K q^{2}\right)^{2} \\
\int_{0}^{L / \epsilon H} \frac{\partial T}{\partial z} \mathrm{~d} x=\frac{L}{H \varepsilon} \frac{K+1}{2} \frac{\mathrm{d}}{\mathrm{d} z}\left(\frac{q}{1+K q^{2}}\right) \\
-2 \frac{\mathrm{d}}{\mathrm{d} z}\left(\frac{q}{v\left(1+K q^{2}\right)}\right) .
\end{gathered}
$$

Thus $Q$ is even in $q$ (and hence $z$ ), so that the top and bottom of the cavity can be treated in the same manner, in contrast to Gill's condition. Requiring zero vertical energy flow at the top and bottom of the cavity, where $q=q_{e}$, gives

$$
\begin{aligned}
& \left(\frac{1}{v^{3}} \frac{\mathrm{d} z}{\mathrm{~d} q}\right)_{q_{\mathrm{e}}} \\
& =\frac{L \varepsilon(K+1)\left(1-K q_{e}^{2}\right) / 4 H-\varepsilon_{e}^{2}\left(1+K q_{e}^{2} / 3\right) / v_{e}}{1-\varepsilon^{2} q_{e}^{2} v_{e}^{6}(1+K)\left(1+K q_{e}^{2}\right)^{3} / 12}
\end{aligned}
$$

The second term in the denominator of the RHS of equation (28) will always be small compared to unity and can be neglected. For $K$ different from minus one, the first term in the numerator dominates and

$$
\begin{aligned}
C^{7}= & 4(K+1)\left(L / H R a^{1 / 7}\right)^{7 / 4} \\
& \times\left(1-q_{e}^{2}\right)^{(10 K-18) / 3(K+2)} \\
& \times\left[1+K(2+K) q_{e}^{2}\right]^{\left(17 K^{2}+72 K+83\right) / 3(K+1)(K+2) /} \\
& {\left[3+4 K-K(3 K+5) q_{e}^{2}+K^{3} q_{e}^{4}\right] } \\
& \times\left(1+K q_{e}^{2}\right)^{8 / 3}\left(1-K^{2} q_{e}^{2}\right)^{8 / 3}
\end{aligned}
$$

As $K$ approaches minus one (more precisely, for $P r \ll$ $\left.(H / L R a)^{1 / 4}\right)$, the second term in the numerator will become as important as the first, and must be included in the calculation for $C$.

Gill's result is obtained from equation (28) in the limit as $R a^{1 / 7} H / L$ approaches infinity. For the large Prandtl number limit, Bejan shows that $C\left(H R a^{1 / 7} / L\right)^{1 / 4}$ can be up to $30 \%$ higher than Gill's result.

For engineering applications, the important result is the overall Nusselt number, defined as

$$
N u=-\left.(L / \varepsilon H) \int_{-1 / 2}^{1 / 2} \frac{\partial T}{\partial x}\right|_{x=0} \mathrm{~d} z .
$$

For the present solution, this results in

$$
\begin{aligned}
N u(R a L / H)^{-1 / 4}=\left(C^{3} / 8\right) \int_{-q_{e}}^{q_{e}} \mathrm{~d} q(1-q)^{2}(1-K q)^{2} \\
\times\left(1-K^{2} q^{2}\right)\left[4 K+3-K(3 K+5) q^{2}+K^{3} q^{4}\right] / \\
\quad\left(1+K q^{2}\right)\left(1-q^{2}\right)^{2(K-1) /(K+1)} \\
\times\left(1+K(2+K) q^{2}\right)^{\left(9 K^{2}+36 K+39\right) / 3(K+1)(K+2)}
\end{aligned}
$$

\section{RESULTS AND DISCUSSION}

The results of the numerical integration of the 

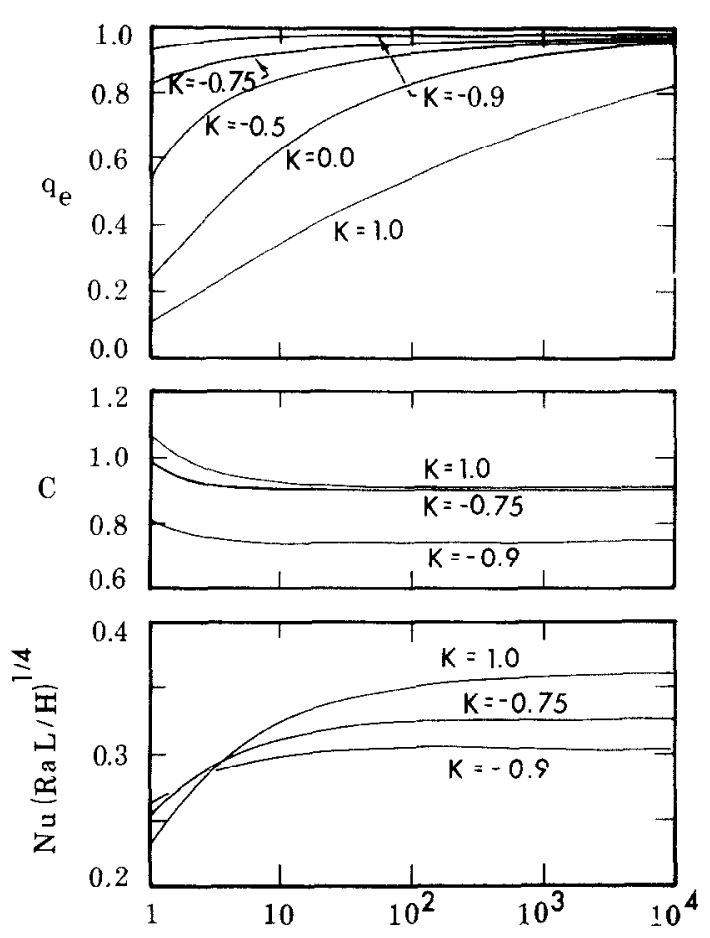

Fig. 1. The dependence of $q_{e}, C$, and Nusselt number on the length ratio and Rayleigh and Prandtl numbers.

preceding equations are given in Figs. 1-6 as functions of $K$ and the combination $R a^{1 / 7} H / L$. The Nusselt number results are also given in Table 1. The parameter $N u(R a L / H)^{1 / 4}$ is seen to decrease only slightly with decreasing Prandtl number, varying less than $20 \%$ when the Prandtl number is decreased from infinity to 0.05 . Decreasing Prandtl number brings $q_{e}$ closer to unity. As pointed out by Bejan, values of $q_{e}$ less than unity imply that the fluid entering the boundary layers at the top and bottom of the cavity has finite vertical velocity. Thus, this velocity decreases with decreasing Prandtl number.

An interesting effect due to the Prandtl number can be seen from equation (23). When $K=-0.75(\mathrm{Pr}=$ $1 / 7), \mathrm{d} z / \mathrm{d} q$ vanishes at $q=0$, and hence the temperature gradicnt at that point becomes infinite. Lower values of $K$ in fact make $z$ multi-valued in $q$, which is not admissible. The explanation would appear to be that, since the horizontal velocity component is zero along the horizontal centerline of the cavity, there is insufficient heat transfer between the boundary layer and the core in this region for $P r<1 / 7$. The solution suggests the need for a shear layer along this centerline to remove the discontinuities in temperature and velocity which develop. It is reasonable to assume that the present solution is still applicable above and below this shear layer. The integration of equation (23) would then commence from $q_{0}$ rather than zero, where $q_{0}$ is the value of $y$ at which $\mathrm{d} z / \mathrm{d} q$ vanishes. Thus.

$$
y_{0}^{2}=\left[3 K+5-\sqrt{2}\left(25+18 K-7 K-12 K^{2} .\right.\right.
$$

The implication of this change in the interval of integration is that the original scaling of the coordinates is becoming less appropriate. Since the approximate equations (5) and (6) are linear, all information is still preserved in the solution, but finer steps in the integration procedure may bc necessary.

The stream function $\psi_{0}$ is a measure of the flow rate in the boundary layer. As the Prandtl number decreases, so do $T_{0}$ and $\psi_{0}$ and thus the boundary layer flow rate. For values of $R a^{1 / 7} H / L$ near unity (when in all likelihood the theory is not valid), the values of $\psi_{0}$ near the cavity top and bottom differ substantially from zero, while for larger values of this parameter it is nearly zero. Thus for most of the range of the Rayleigh number considered, there is little flow rate in the top and bottom boundary layers.

On the basis of experiments in air, Yin et al. [4] suggest that the present theory should be valid for $R a$ $>(10 H / L)^{4} \mathrm{Pr}$. No upper limit is given by them but Macgregor and Emery [5] suggest $R a<10^{6} \mathrm{Pr}$, giving no explicit form for the length ratio dependency. Y in suggests that the slopes of the lines separating the conduction, transition and convection regions are the same. If this holds true for the postconvection region as well, then $R a<10^{6}(H / L)^{4} P r$.

The present approach would appear to be applicable to more general cavity shapes, and for other than adiabatic top and bottom walls. It is not, however, suited for non-horizontal walls which are adiabatic, for once the stream function is determined, only the ratio $T_{0} / \psi_{0}$ remains to be adjusted in the expression for
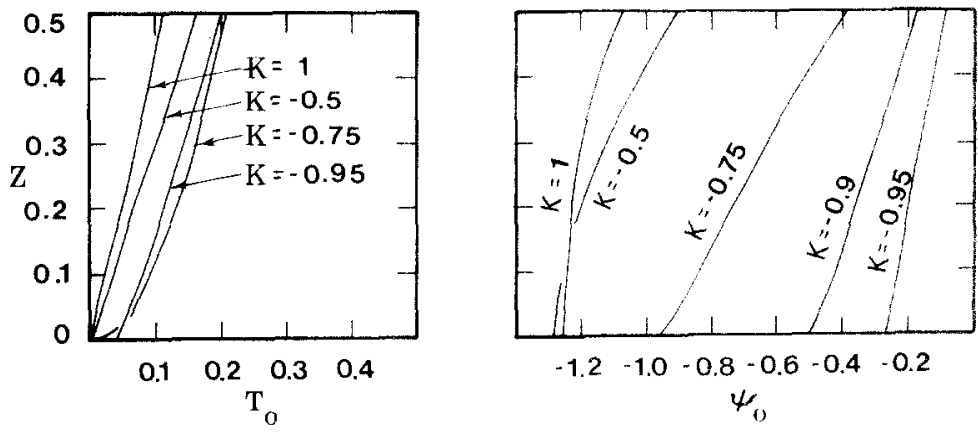

FIG. 2. Core temperature and stream function for $R a^{177} H / L=1$ 

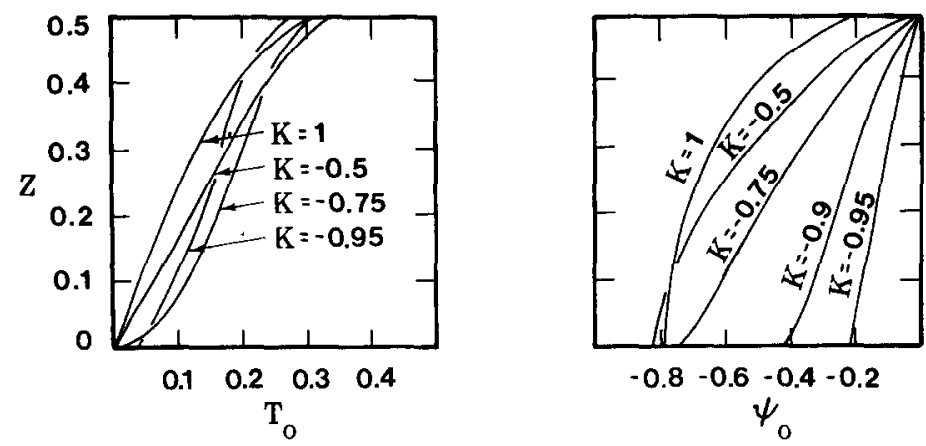

Fig. 3. Core temperature and stream function for $R a^{1 / 7} H / L=10$.
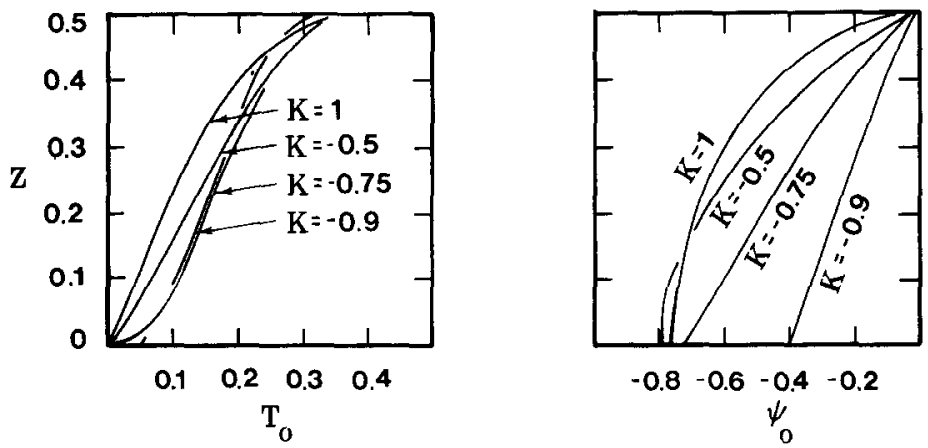

FIG. 4. Core temperature and stream function for $R a^{1 / 7} H / L=100$.
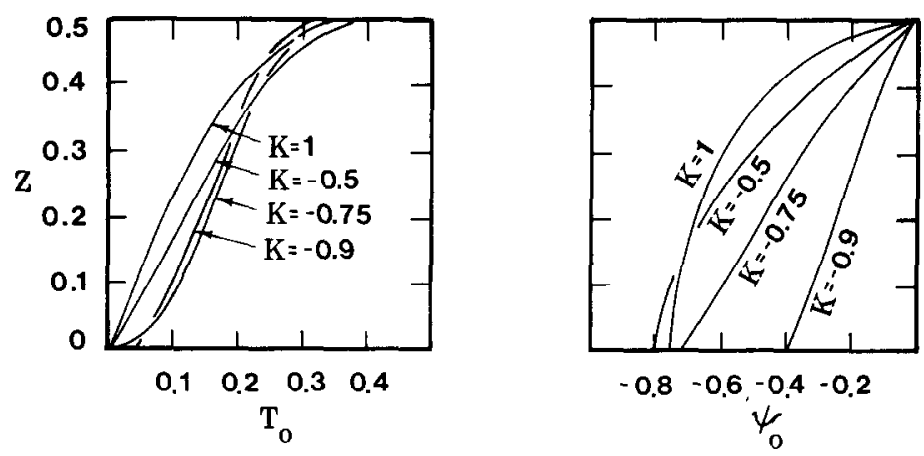

Fig. 5. Core temperature and stream function for $R a^{1 / 7} H / L=1000$.
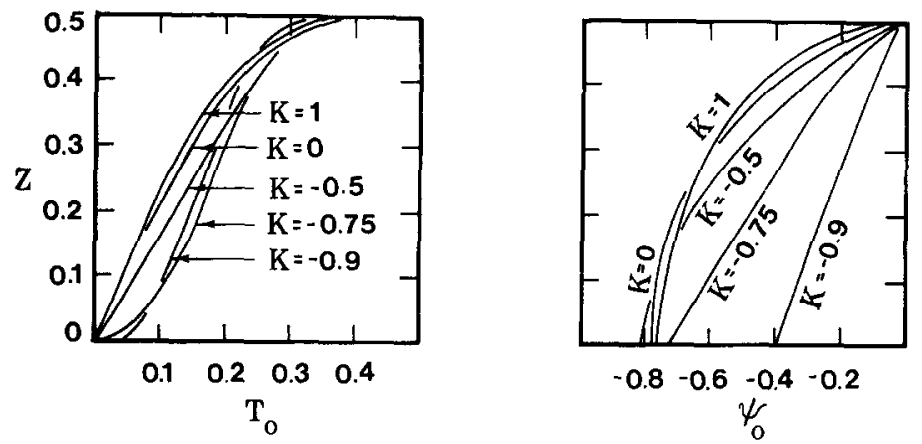

FIG. 6. Core temperature and stream function for $R a^{1 / 7} H / L=10000$. 
Table 1

\begin{tabular}{|c|c|c|c|c|c|}
\hline \multirow[b]{2}{*}{$R a^{17} H L$} & \multicolumn{5}{|c|}{$N u(R a L / H)^{-1.4}$} \\
\hline & $\begin{array}{c}K=-0.9 \\
\operatorname{Pr}=0.05263\end{array}$ & $\begin{array}{l}K=0.75 \\
P r=0.1429\end{array}$ & $\begin{array}{c}K=-0.5 \\
P r=0.3333\end{array}$ & $\begin{array}{c}K-0 \\
P r=1.0\end{array}$ & $\begin{aligned} k & =1 \\
\operatorname{Pr} & =1\end{aligned}$ \\
\hline 1 & 0.2557 & 0.2554 & 0.2409 & 0.2366 & 0.2402 \\
\hline 2 & 0.2781 & 0.2838 & 0.2819 & 0.2727 & 0.2749 \\
\hline 4 & 0.2905 & 0.3019 & 0.3093 & 0.3034 & 0.3043 \\
\hline 7 & 0.2985 & 0.3112 & 0.3232 & 0.3220 & 0.3223 \\
\hline 10 & 0.3012 & 0.3153 & 0.3295 & 0.3310 & 0.3313 \\
\hline 100 & 0.3094 & 0.3262 & 0.3455 & 0.3560 & 0.3578 \\
\hline 1000 & 0.3108 & 0.3279 & 0.3480 & 0.3601 & 0.3623 \\
\hline 10000 & 0.3110 & 0.3282 & 0.3484 & 0.3606 & 0.3629 \\
\hline
\end{tabular}

\title{
REFERENCES
}

temperature. For adiabatic walls, this vanishes and there are then no adjustable parameters. Most present theories of stratified flows have this difficulty. The theory of Walin [6] and Rahm and Walin [7] for instance is designed for the case where the normal temperature gradient is proportional to temperature. The theory breaks down as the constant of proportionality vanishes. Further, it neglects the convective terms completely, and thus is suited for much slower flows than the present theory.

Acknowledgements The author wishes to express his gratitude to the Centre d'Etudes Nucléaires de Grenoble France for support during a sabbatical year. Particular gratitude is due messieurs Costa, Delhaye and Grand of that institute.
1. A. E. Gill, The boundary-layer regime for convection in a rectangular cavity, J. Fluid Mech. 26, 515-536 (1962).

2. A. Bejan, Note on Gill's solution for free convection in a vertical enclosure, J. Fluid Mech. 90, 561-568 (1979).

3. G. F. Carrier, On the integration of equations associated with problems involving convection and diffusion, in Proceedings of the 10th International Congress on Applied Mechanics. pp. 150-151. Elsevier, New York (1960).

4. S. H. Yin, T. Y. Wung and K. Chen, Natural convection in an air layer enclosed within rectangular cavities, Int. $J$ Heat Mass Transfer 21, 307-315 (1978).

5. R. K. MacGregor and A. F. Emery, Free convection through vertical plane layers-moderate and high Prandtl number fluids, J. Heat Transfer 91, 391-402 (1968).

6. G. Walin, Contained non-homogeneous flow under gravity, or how to stratify a fluid in the laboratory, $J$. Fluid Mech. 48, 647-672 (1971).

7. L. Rahm and G. Walin, Theory and experiments on the control of the stratification in almost-enclosed regions, $J$. Fluid Mech. 90, 315-325 (1979).

\section{INFLUENCE DU NOMBRE DE PRANDTL SUR LA CONVECTION NATURELLE DANS UNE CAVITE RECTANGULAIRE}

\begin{abstract}
Résumé On considère la convection naturelle dans une cavité rectangulaire dans le cas oủ une paroi verticale est chauffée tandis que l'autre est refroidie. L'écoulement de couche limite est traité en utilisant une technique modifiée d'Oseen de façon semblable à la solution de Gill. Les profils de température et de vitesse dans le noyau, et le nombre de Nusselt sont donnés en fonction des nombres de Rayleigh et de Prandtl et du rapport d'allongement. La solution montre que pour un nombre de Prandtl inférieur à $1 / 7,11$ se développe une couche de cisaillement à mi-section.
\end{abstract}

\section{DER EINFLUSS DER PRANDTL-ZAHL AUF DIE FREIE KONVEKTION IN EINEM RECHTWINKLIGEN HOHLRAUM}

Zusammenfassung - Freie Konvektion in einem rechtwinkligen Hohlraum wird für den Fall untersucht, bei dem eine senkrechte Wand geheizt und die andere gekühlt wird. Die Grenzschichtströmung wird mit Hilfe einer modifizierten Methode nach Oseen ähnlich der Lösung von Gill berechnet. Temperatur- und Geschwindigkeitsprofile im Kern sowie die Nußelt-Zahl ergeben sich als Funktioner der Rayleigh- und Prandtl-Zahl und des Längenverhältnisses. Das Ergebnis zeigt, daß sich für Prandtl-Zahlen kleiner als 1/7 eine Scherströmungsschicht im Mittelschnitt ausbildet. 


\section{ВЛИЯНИЕ ЧИСЛА ПРАНДТЛЯ НА СВОБОДНУЮ КОНВЕКЦИЮ В ПРЯМОУГОЛЬНОЙ ПОЛОСТИ}

Аннотаияя - Проведено исследование естественной конвекции в прямоугольной полости, одна из стенок которой нагревается, а другая охлаждается. Решение для течения в пограничном слое получено с помощью модифицированного метода Озеена аналогично решению Джилла. Профили температуры и скорости в ядре потока и число Нуссельта определялись как функции чисел Релея и Прандтля и отношения длин сторон. Показано, что при значениях числа Прандтля, меньших 1/7, по миделеву сечению развивается сдвиговой слой. 